\title{
Presidential address - the Black Swan: ISPN and pediatric neurosurgery in times of COVID-19
}

\author{
José Francisco M. Salomão ${ }^{1,2}$ (D)
}

Received: 17 July 2021 / Accepted: 21 July 2021 / Published online: 6 August 2021

(c) The Author(s), under exclusive licence to Springer-Verlag GmbH Germany, part of Springer Nature 2021

Dear Friends and Colleagues,

I am addressing to you in a quite different way I intended when I received the Poncho. Until the seventeenth century, all swans were believed to be white in color and the discovery of black swans in Western Australia in 1697 was a great surprise. This concept was used by Nassim Nicholas Taleb, a mathematician and risk analyst to highlight events of great proportions, high-impact, that were unpredictable and of indefinite duration [1]. The COVID-19 was a Black Swan that caused one of the biggest challenges the humanity has already experienced, comparable to wars, due to the devastating health, economic, social, and psychological effects that it brought with.

Therefore, it's impossible, when I deliver my last message to our Membership, do not address on the SARS-CoV-2 pandemic as testimony of an era and its impacts on ISPN during almost two years.

\section{Epidemics and pandemics: historical background}

Epidemics and pandemics have devastated mankind since immemorial times and have been firstly attributed to divine wrath that announced through natural phenomena such as eclipses, comets, and meteors. Afterwards, it was admitted

First of all, I want to thank thekind words of my dear friend Wolfgang Wagner whom I, by coincidence, succeededboth as Chairperson of the Annual Meeting in 2014 and as President of ISPN in thisunusual term that lasted two years.

José Francisco M. Salomão

jfsalomao@gmail.com

1 Pediatric Neurosurgery Division, Department of Pediatric Surgery, National Institute of Women, Children and Adolescents Health Fernandes Figueira (IFF - Fiocruz), RJ, Rio de Janeiro, Brazil

2 Rio de Janeiro, Brazil that fetid odors in contaminated and poisonous soils, the miasmas, were the cause of diseases such as malaria and plague. Epidemics and pandemics had long been related to wars, natural catastrophes, and migrations. As crowding increased within the walls of ancient cities, germs found ideal conditions to proliferate amidst poor hygiene and sanitation. Mediterranean coastal cities were site of intense commercial exchanges and the preferred targets of pathogenic agents that arrived in ships from distant countries and subsequently spread inland. New roads allowed diseases to reach areas farther from the sea at higher speed. At those times, epidemics were generically labeled as plague, although many were not caused by the plague bacillus but related to other infections such as smallpox, typhus, typhoid fever, cholera, or malaria [2].

The first recorded pandemics left clues to their retrospective diagnosis, based on the testimonies of chroniclers and historians of the period. Thucydides, in his History of the Peloponnesian War, provided detailed information about the Plague of Athens, in 439 BC (Fig. 1); Galenus of Bergama (Fig. 2) reported on the Antonin Plague (166 AD); and Procopius of Caesarea documented the Justinianic Plague (532 AD). These outbreaks were posteriorly recognized as typhoid fever, smallpox, and bubonic pest, respectively. The Black Death began circa 1347, lasted four hundred years, wiped out almost a third of Europe's population, and was documented in Giovanni Boccaccio's The Decameron (Fig. 3). In all aforementioned examples, precise information was possible only after analysis of DNA extracted from skeletal remains as pulp teeth since the end of the twentieth century [3-6].

The Spanish flu pandemic of 1918, caused by Influenza virus $\mathrm{H} 1 \mathrm{~N} 1$, is regarded as the most deadly pandemic the world has ever faced [5]. Since then, several other strains of the Influenza species emerged and were named as Asian, Hong Kong, Swine, and Mexican flues, among others. Coronaviruses have been identified in humans as cause of common colds since the mid-1960s 
Fig. 1 Plague in an Ancient City (Michiel Sweeters, ca. 1654) depicts the plague of Athens, probably typhoid fever. Some experts believe that this epidemic took place in Rome in 361-363 AD under the rule of emperor Julian. From: https:// commons.wikimedia.org/wiki/ File:Michiel_Sweerts_and_ Workshop_-_Plague_in_an_ Ancient_City.jpg

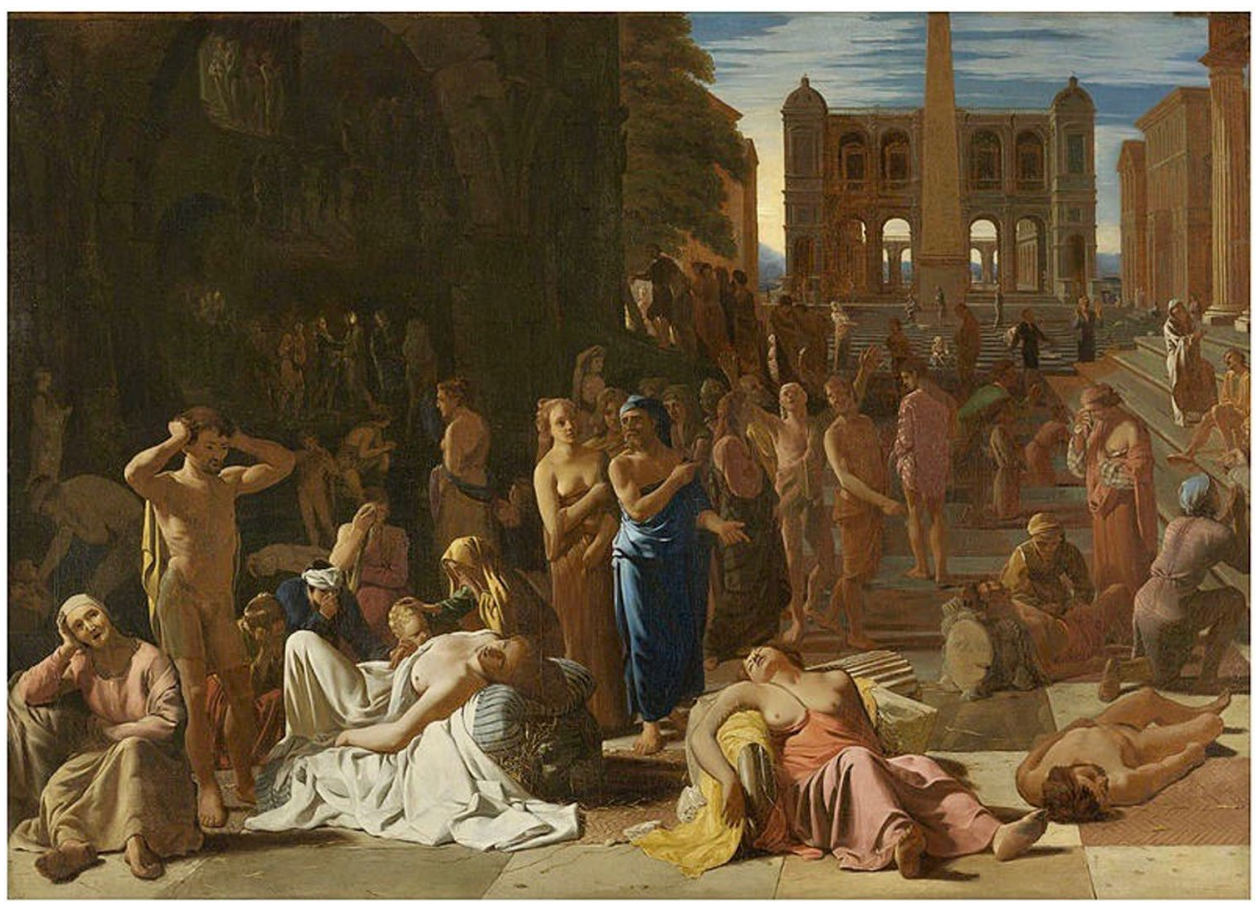

and also responsible for the outbreaks of Severe Acute Respiratory Syndrome (SARS) 2002 epidemic, the Middle East Respiratory Syndrome (MERS), and the COVID19 pandemic [6].

\section{COVID-19: an overview}

Since the first report in Wuhan, China, in December 2019, the novel human coronavirus disease led to unexpected, intense, and dramatic changes all over the world, affecting health and economy, disrupting routines and behaviors as a whole. Personal and professional plans were abruptly modified; millions of lives were suddenly and unexpectedly taken and we had to face a new reality while waiting for an uncertain future we suspected would be different from everything we once knew.

In January 2019, when only one case had been detected outside China, several epidemiologists believed that COVID-19 would not result in major problems and would be contained within the borders of the country of origin. This feeling resulted from a lack of knowledge and relevant information about the disease that left the impression one was dealing of a case of a "mild flu" and that no lesson was learnt from past pandemics. China adopted several measures to slow down the infection rates that included lockdown and social distancing, reducing transmission by about $60 \%$. The first WHO alert on SARS-CoV-2 was issued on December 31,2019 . One month later, it was declared a "public health emergency of international concern." This status has been used previously in rare situations requiring a strong international response. On March 11, 2020, the WHO raised the contamination status to pandemic, due to the rapid geographical spread of the virus. COVID-19 was then considered the fifth pandemic following 1918 Spanish flu [7].

Just like the customs of the "plague doctors" in seventeenth century (Fig. 4), personal protective equipment (PPE)—facemask, gowns, and goggles-was reintroduced globally to protect population and health care professionals (HCP). PPE along with social distance and basic hygiene measures became the main weapon to minimize virus dissemination [8]. Since the beginning of the pandemic, HCP are at increased risk, especially when exposed to aerosols, secretions, and prolonged and close contact with infected patients [9].

As expected, the literature on COVID-19 increased exponentially since the first reported cases. About 4000 publications could be recovered in a Medline search just one month after WHO raised COVID-19 status to pandemic [10]. Currently, (July 4th, 2021) there were in PubMed database alone roughly 150,000 related publications on COVID-19. Probably, by the time this message is published, the numbers of reports will have increased even more and a new face of the disease will likely have appeared, due to the unpredictable characteristics of this virus. 


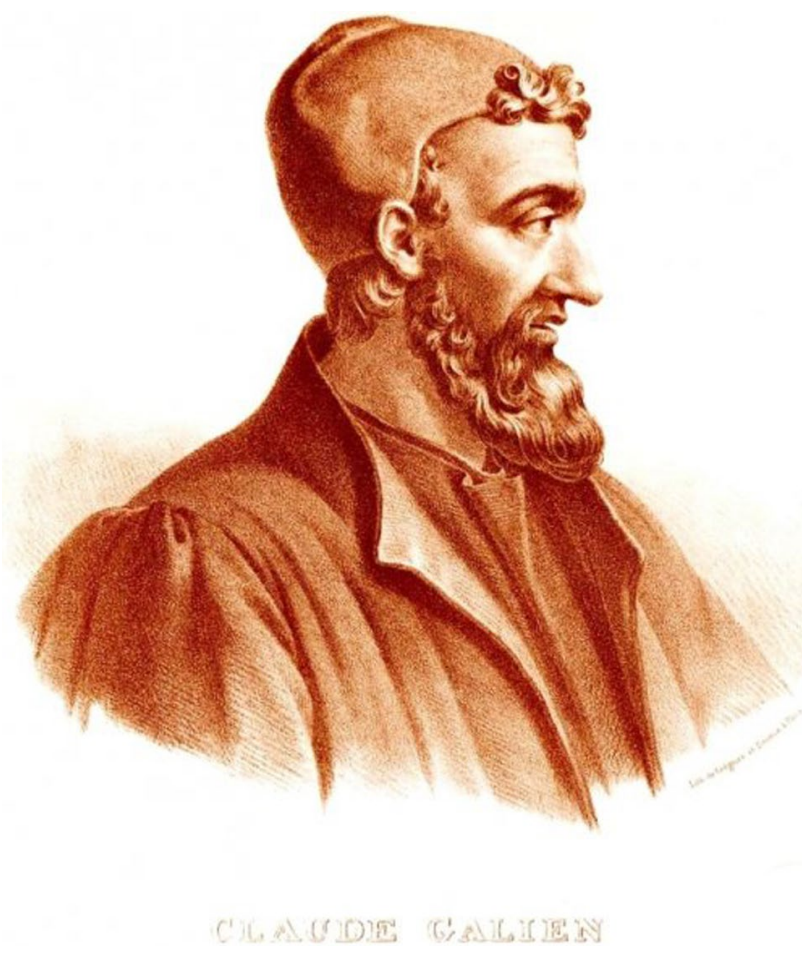

Fig. 2 Galenus of Bergama reported the Antonin Plague (166 AD), named after the roman emperor Marcus Aurelius Antoninus. It occurred when Rome enjoyed a period of prosperity and expansion with good conditions of hygiene and sanitation and was later on identified as smallpox. From: https://commons.wikimedia.org/wiki/File: Claude_Galien_CIPC0108.jpg

\section{Children and COVID-19}

Contrary to initial assumptions, COVID-19 may not be as rare in children, but it has a milder course and is less symptomatic, with most cases linked to familial clustering [11, 12]. Actually, the risk of transmission of severe infection appears to be lower from a child to an adult than the reverse [12]. It is also suggested that children may not transmit SARS-CoV-2 as efficiently as adults but additional studies are needed to clarify their role in the transmission dynamics of the virus [13].

Although rarely affected by the virus itself, due to the lockdown imposed in most of the countries, children presented with mood and behavior changes leading to longlasting psychological or psychiatric disorders [14, 15]. Older children were specially impacted by the closure of schools and introduction of digital home schooling, although changes induced by the public health crisis, social isolation, and economic recession could affect all the family clusters $[16,17]$. The psychological consequences of lockdowns and social distancing in sick children were emphasized by Adduci et al. [17] that stressed the importance of special approaches for some categories, as children and adolescents with cancer.

\section{Peculiarities affecting pediatric neurosurgery}

At the very beginning of the pandemic, recommendations were to minimize, postpone, or cancel electively scheduled operations. Critically or potentially ill patients had to be identified and non-urgent procedures were postponed, particularly if there was a high risk of prolonged stay in intensive care units. Outpatients clinics were closed and elective patients were evaluated remotely through phone calls, e-mails, or teleconsultation [18, 19]. Several centers restricted activities to the care of trauma, shunt procedures, vascular surgeries, and cases of malignant tumors, and cord compression. Treatments were deferred and temporizing measures such as external ventricular drainages or reservoirs implants were sometimes adopted and subjected to the limitations and hazards proper to the procedures. Chemotherapy was temporarily delayed. Overall, there was a significant decrease in the volume of pediatric cases [18, 20]. According to a survey conducted by Jean et al. [20], one-half of the responders reported a drop of about $50 \%$ in total operative volume. A similar study conducted by the Brazilian Society of Pediatric Neurosurgery informed that $90.7 \%$ of the neurosurgical activity was compromised and overall elective neurosurgical procedures were cancelled or postponed in $57.3 \%$ of the cases [18].

Since elective surgeries experienced a significant decline in volume, the pediatric neurosurgery facilities in general hospitals were converted to adult COVID-19 beds. Pediatric emergency was often reallocated and equipment like respirators was reassigned. Elective patients requiring admission and/or surgery were whenever possible transferred to specific units [21-23]. Pediatric hospitals, due to their characteristics were at lower risk although many, at the epicenter of the pandemic, had to accommodate critically ill adults [21, 22].

As the health care personnel (HCP) responsible for these COVID-19 patients were overwhelmed, some specialists were reassigned to areas of greatest need, with additional training quickly provided. Consequently, young doctors and residents were summoned and the latter had their training interrupted [21, 24-26].

Patients whose treatment had been postponed or cancelled were at risk, a peculiar and dangerous situation in which they could become potential collateral victims [25]. Urgent procedures, here defined as those to be resolved within one day to four weeks, were deferred as much as possible [27]. Shortly after the beginning of the pandemic, the dichotomy 
Fig. 3 A tale from the Decameron (J.W. Waterhouse, 1916) depicts a scene from Boccaccio's Decameron. The storytellers, seven girls and three boys, confined themselves to a castle near Florence to escape the Black Death. From: https:// commons.wikimedia.org/wiki/ File: Waterhouse_decameron. jpg

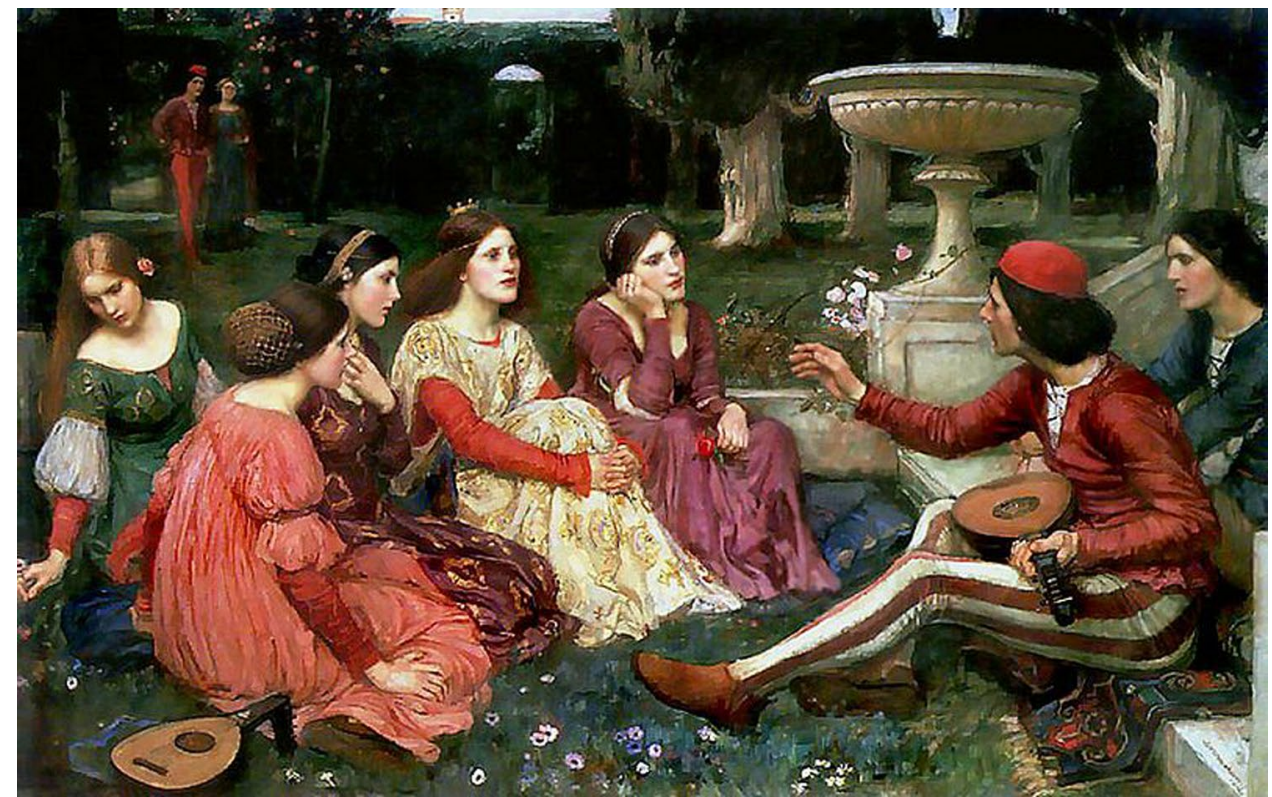

of elective versus urgent intervention was deemed inadequate and pediatric neurosurgery priorities were defined in a case-to-case basis. Minimizing the risk of neurological deterioration and postponing surgeries indefinitely can have tragic consequences. Therefore, pediatric cases were riskstratified to give a surgical response in the appropriate time. This concept is recommended to diseases, malignant or not, at risk of sudden deterioration [26]. These situations also applied to closed neural tube defects and craniosynostosis that cannot be postponed indefinitely and which delays may lead to the loss of the ideal treatment timing. Actually, there are very few pediatric neurosurgical pathologies that can be postponed for extended periods of time.

Several pediatric trauma centers reported $50 \%$ reductions in patient volume at emergencies during the first months of pandemic $[28,29]$. Fewer outdoor activities and school closure led to a significant decrease in the number of fractures requiring surgery but, conversely, it lead to an increase in domestic trauma [30]. Reduction in activity away from home may be a reasonable explanation for the drop in trauma referrals since parents and patients feared to go to the hospital $[14,24]$. The reduction of referral may also be ascribed to the lower number of trivial or ill-identified problems [28] and also the implementation of virtual consultations [27]. Notwithstanding, some centers noticed an increase in emergency services volume, yet without statistically significant differences [29].

An increase of non-accidental head injuries (NAI) has been reported during the current pandemic. A regional pediatric trauma center in the UK reported a near fourfold increase in admissions for suspected NAI [31]. Dyson et al. [29] reached similar results but reported a significant increase in intracranial hemorrhage, while Petrowski et al. reported an increase in overall calls to helplines directed at children [32]. Conversely, suspected cases of NAI decreased by $42 \%$ in Denmark probably due to unreported child abuse during the same period [33]. These results reinforce the need of greater awareness during periods of social distancing and some other protective strategies, as the availability of helplines, even in the absence of restrictions to remain at home.

Pediatric patients and/or caregivers were usually unaware of the possibility of SARS-CoV-2 infection when arriving to ER and testing was not always possible before emergent surgery. Patients with scheduled non-emergent surgery and those undergoing aerosol-producing procedures such as intubation and endoscopic procedures in general require preoperative testing [19, 34].

\section{The ISPN and the pandemic}

Societies and associations in most of the affected countries focused on recommendations that included triage, adaptation of neurosurgical departments, resident's education, and concerns on PPE correct use in current neurosurgical practice $[10,18,35]$. Although these recommendations are being gradually relaxed in countries that have already gained greater control over the pandemic, restrictions may need to be resumed to the crisis level and this has actually happened in many cities and countries.

The ISPN officially started to address the pandemic at the virtual Executive Board (EB) Meeting of February 24, 2020. At that time, the overall concern was not so overt but there were already signs that the outbreak could spread out 


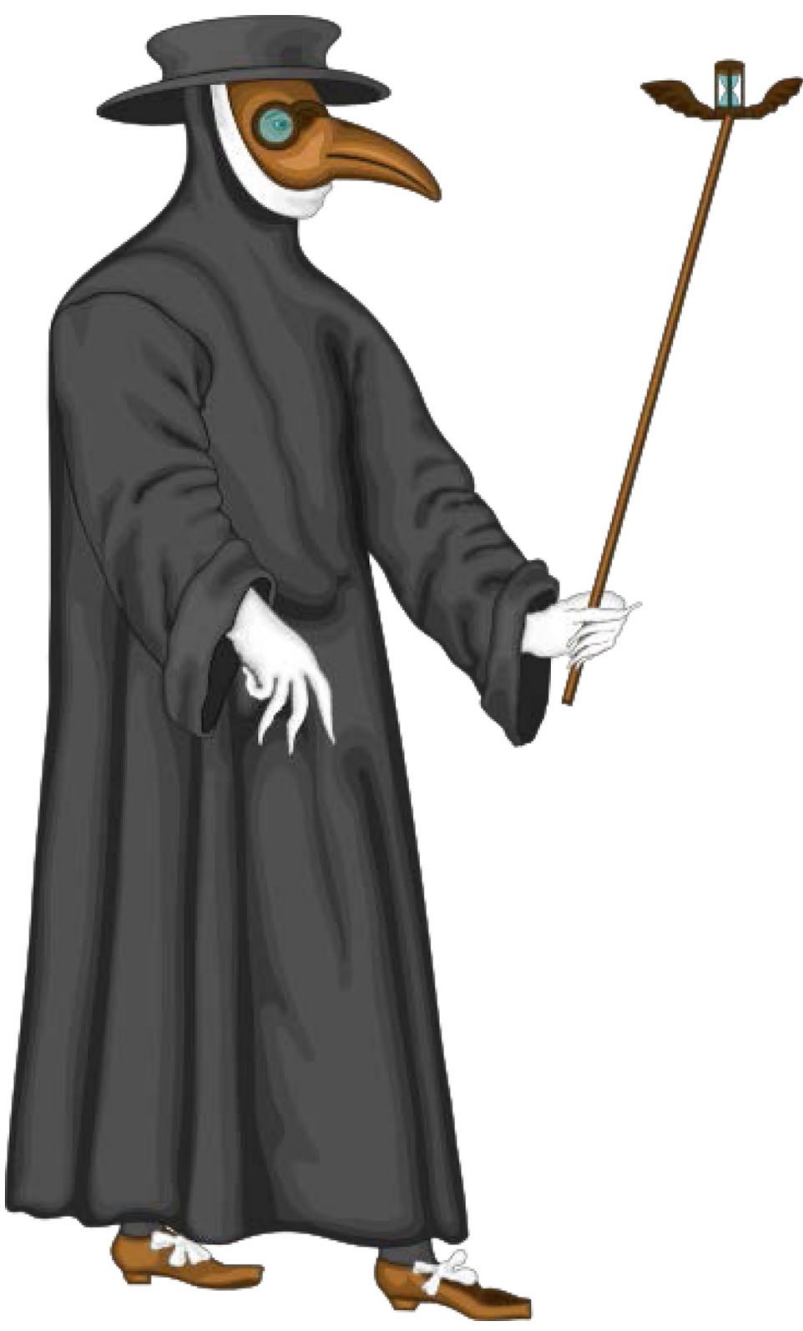

Fig. 4 Pest doctors in the seventeenth century wearing a protective outfit that included boots, a leather coat with long sleeves, hat, gloves, a rod, and a mask with an elongated beak filled with scented spices and perfumes so that they could approach and examine the extremely fetid patients. From: https://commons.wikimedia.org/wiki/File: Plague_Doctor.svg

of Asia. Despite the increasing news of virus dissemination, the dates of the Annual Meeting were maintained. Shortly after March 11, 2020, the EB decided to postpone all events for one year. It was also decided to maintain or "freeze" the EB members and officers, postponing all the elections to 2021. The five consecutive year rule for members to rotate off the EB was suspended and those who would normally be rotating off the EB continued.

There was an intense movement towards maintaining our scientific and educational activities. The Scientific Committee tirelessly organizing a pioneering Virtual Meeting of a 3 days program, from 6 to 8th November 2020, whose topic was Cutting Edge Updates in Pediatric Neurosurgery. This was a low-cost event with registration free of charge for everyone, broadcasted through Zoom and YouTube.
This event exceeded expectations and there were in average 800 attendees. There were a substantial number of no ISPN guest speakers and a Forum Session discussed how to address education and training at the time of COVID19. A poll conducted on this subject showed that most of the respondents were experiencing problems to fulfill the requirements of their training program, that virtual events and programs as well as daily clinical activities were not sufficient either. However, the majority considered that their training was not yet at risk (Fig. 5). The Education Committee anticipated the results of this poll and in the first semester of the year 2020 start organizing webinars, appropriately known "Clash of Titans" in which relevant and controversial topics were presented by experts facing each other, one for and one against and enthusiastically discussed by the attendants (Fig. 6). This proved to be an important information tool to the neurosurgical community, at a time all face-toface activities had been suspended. Online meetings were also organized to replace our traditional courses around the world. The Communication Committee streamlined the webpage and expanded the WhatsApp group's activities beyond information during meetings and courses and, operating continuously, greatly facilitated communication between the EB members. Furthermore, during this period, the Membership Committee launched a campaign, which, with the participation of a task force involving colleagues from around the world, recruited significant numbers of new members.

Due to the persistence of adverse conditions that still impairs face-to-face gatherings, a second Virtual Meeting is currently being organized and the Singapore Meeting was again postponed and scheduled to 6-10 December 2022, forcing some new strategies, in addition to an added cost to the expenses already committed.

It is worth noting the tireless work of the ISPN officers and all the EB Members who gave the President the support he needed during these two difficult years, keeping the ISPN Family active and united. Last but not least, our partner Kenes who gave a considerable contribution in keeping the Society working in adverse conditions.

\section{Future perspectives}

Obviously, everyone is longing to get back to the good old times with hugs, hand-shaking, friendly conversation, and other manifestations of affection during coffee breaks, lunch lines, and social programs, when we reconnect with old friends and became acquainted to new ones.

Face-to-face meetings have been one of the most traditional and valuable ISPN's legacy. However, virtual events proliferated in times of distancing, in our perception, are here to stay even after the return of face-to-face activities. Virtual activities have proven to be cost-effective, 


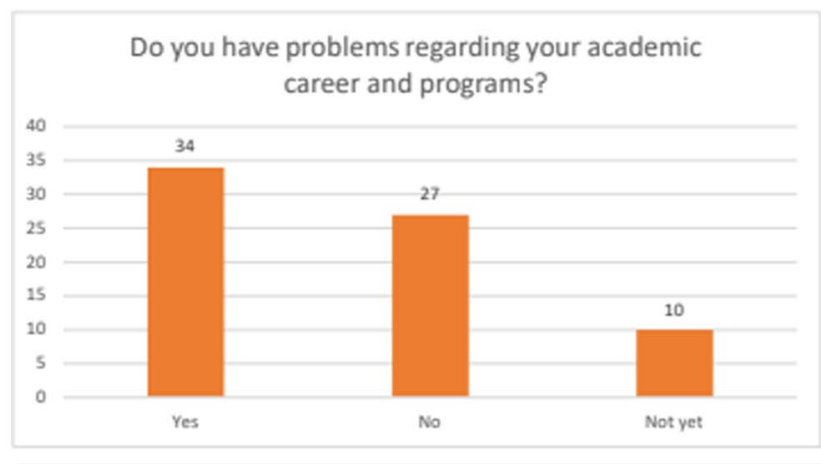

Do you feel your daily clinical training / education in times of the pandemic sufficient?

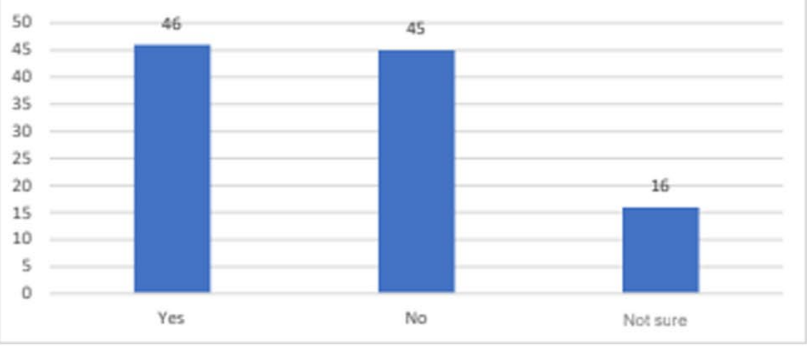

Are virtual events and programs sufficient for your education and training?

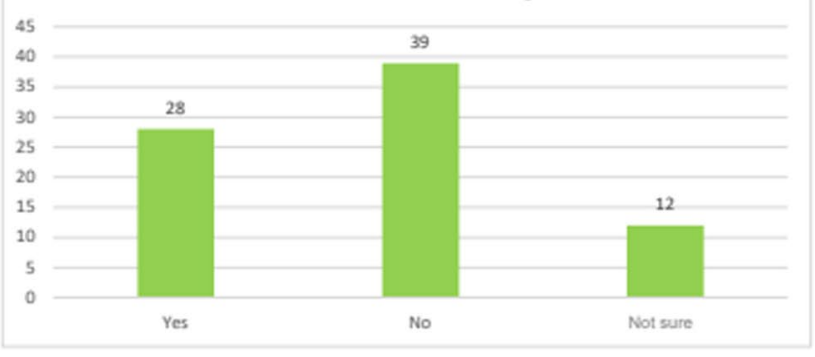

Is your specialist training at risk?

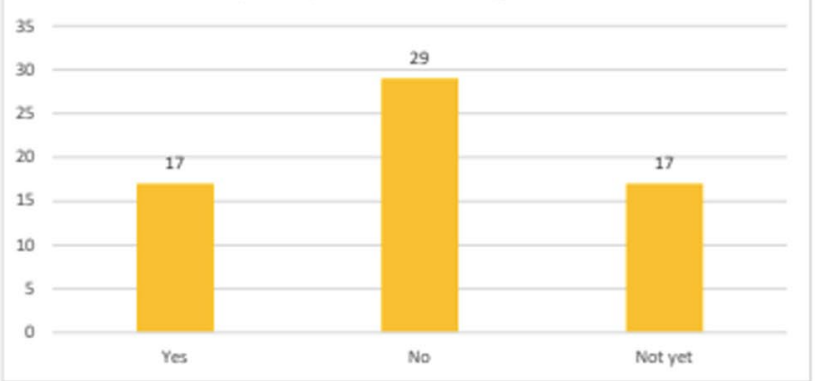

Fig. 5 Education and training in times of COVID-19. Results of a poll conducted by ISPN's Education, Scientific and Liaison Committees, December 2020

accessible to a larger audience with no traveling or lodging expenses, and responsible for a positive impact on the environment [36]. Additionally, a favorable response to video conferencing both from trainees and faculty was detected, as well as the feeling that they would in part replace traditional meetings, discussion of cases, journal clubs, and other activities such as neuroanatomical training with 3D models [37, 38]. Consequently, one may
Fig. 6 Print screen of the first Clash of the Titans webinar "In Pediatric Neurosurgery Prenatal Radiological Investigations Do Not Serve Any Use," June 2020

\section{NEUROSURGERY PRENATAL RADIOLOGICAL INVESTIGATIONS DO NOT SERVE ANY USE}

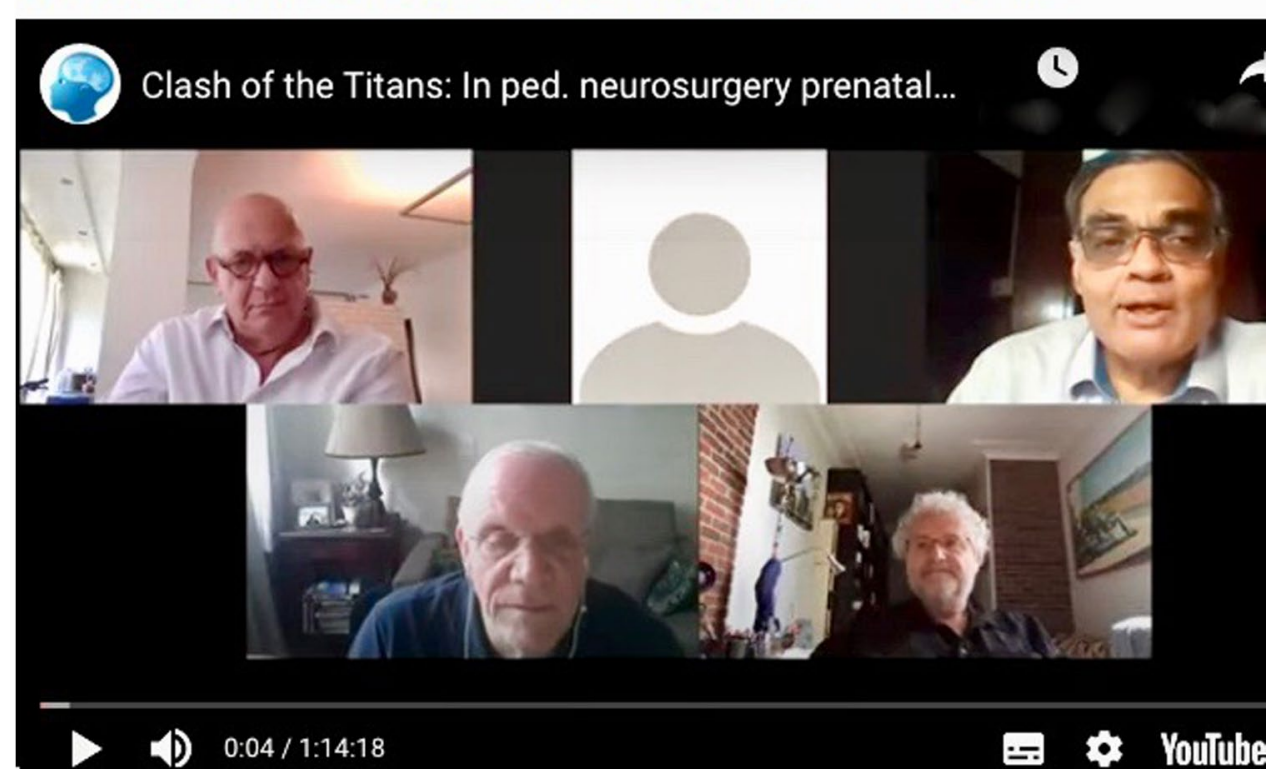


deem a hybrid format of meetings, virtual plus face-toface, that will allow more inclusive education activities at reduction of costs. Adaptation and creativity will be of utmost importance in this transition, considering that the main sources of funding from societies as ISPN are annual membership as well meetings and courses fees.

\section{The life post COVID-19}

Being back to a "new normal" depends on development of new treatments, successful vaccination, and prevention of future COVID-19 outbreaks as well as proper safety protocols. Comparing the data collected during and after lockdown, the department of pediatric neurosurgery of a children's hospital in Genoa, Italy, showed that, in the latter group (after lockdown), no positive testing was observed and no surgery was postponed [39]. Pediatric neurosurgery activities are back and gradually the services resumed their routines while observing protocols and safety guidelines in wards and outpatients unities.

\section{Final considerations}

The pandemic is testing the health systems to their limits and exposing their fragility. The pandemic exposed the shortage of hospital beds, human resources, and even of low-cost PPE such as facemasks and gloves. It also unveiled the already known disparities between public and private health care infrastructure in most of the countries, showing that the underprivileged remain the most affected and that the economic recession accentuated inequalities.

More than one year and a half after the beginning of the pandemic and despite the initial progresses achieved in vaccination, we cannot say that it is about to resolve. COVID-19 rates are still very high and are even increasing in some countries. New variants are being found and new waves of novel cases are popping up. It is still not known whether the virus is here to stay with a persistent pattern of mutations or whether it will eventually become seasonal like the H1N1 flu [40].

COVID-19 pandemic is also an environmental crisis. About $70 \%$ of the diseases that emerged since 1940 are of viral origin and associated with an animal-to-human transmission [41]. According to a FAO report, this implies in permanent increased risk of pandemics, food security hazards, and higher burdens of zoonotic diseases [42]. Reduced activities during the lockdown made polluted waters crystal clear again and improved air quality significantly in cities permanently plagued by fog and darkness. Human, animal, and environmental health are linked and the "One Health" concept taught us that we can no longer treat human, animal, and environmental health separately [43].

Acknowledgements To Marcia Cristina da Silva, M.D. who revised this manuscript, my deep appreciation.

\section{Declarations}

Conflict of interest The author has no conflicts of interest to declare that are relevant to the content of this article.

\section{References}

1. Taleb NN (2010) The Black Swan: second edition: the impact of the highly improbable fragility". Random House; 482

2. Wolfe ND, Dunavan CP, Diamond J (2007) Origins of major human infectious diseases. Nature 447(7142):279-283. https:// doi.org/10.1038/nature05775

3. Papagrigorakis MJ, Yapijakis C, Synodinos PN, BaziotopoulouValavani E (2006) DNA examination of ancient dental pulp incriminates typhoid fever as a probable cause of the Plague of Athens. Int J Infect Dis 10:206-214. https://doi.org/10.1016/j.ijid. 2005.09.001

4. Drancourt M, Raoult D (2005) Palaeomicrobiology: current issues and perspectives. Nat Rev Microbiol 3:23-35. https://doi.org/10. 1038/nrmicro1063

5. Agrawal A, Gindodiya A, Deo K, Kashikar S, Fulzele P, Khatib N (2021) A comparative analysis of the Spanish Flu 1918 and COVID-19 pandemics. Open Public Health J 14:128-34. https:// openpublichealthjournal.com/contents/volumes/V14/TOPHJ-14128/TOPHJ-14-128.pdf

6. Ludwig S, Zarbock A (2020) Coronaviruses and SARS-CoV-2: a brief overview. Anest Analg. https://doi.org/10.1213/ANE. 0000000000004845

7. Liu Y-C, Kuo R-L, Shih S-R (2020) COVID-19: the first documented coronavirus pandemic in history. Biomed J 43:328-333. https://doi.org/10.1016/j.bj.2020.04.007

8. CDC Centers for Disease Control and Prevntion. Personal protective equipment. Avaliable at https://www.cdc.gov/niosh/ppe/ Accessed 05 Jul 2021

9. Giri A, Sapkota B, Shrestha R, Khatiwada AP, Tiwari R, Aryal M et al (2021) A narrative review of personal protective equipment uses in coronavirus disease 2019 and its disposable practices. JMA J. 4:86-90. https://doi.org/10.31662/jmaj.2020-0120

10. Germanò A, Raffa G, Angileri FF, Cardali SM, Tomasello F (2020) Coronavirus disease 2019 (COVID-19) and neurosurgery: literature and neurosurgical societies recommendations update. World Neurosurg 139:e812-e817. https://doi.org/10.1016/j.wneu. 2020.04.181

11. Zimmermann P, Curtis N (2020) COVID-19 in children, pregnancy and neonates: a review of epidemiologic and clinical features. Pediatr Infect Dis J 39:469-477. https://doi.org/10.1097/ INF.0000000000002700

12. Zheng F, Liao C, Fan Q, Chen H, Zhao X, Xie Z et al (2020) Clinical characteristics of children with coronavirus disease 2019 in Hubei, China. Curr Med Sci 40:275-280. https://doi.org/10.1007/ s11596-020-2172-6

13. Rajapakse N, Dixit D (2021) Human and novel coronavirus infections in children: a review. Paediatr Int Child Health 41:36-55. https://doi.org/10.1080/20469047.2020.1781356 
14. Raffaldi I, Castagno E, Fumi I, Bondone C, Ricceri F, Besenzon L et al (2021) Pediatric admissions to emergency departments of North-Western Italy during COVID-19 pandemic: a retrospective observational study. The LancetReg Health Eur. 5:100081. https:// doi.org/10.1016/j.lanepe.2021.100081

15. Larsen L, Helland MS, Holt T (2021) The impact of school closure and social isolation on children in vulnerable families during COVID-19: a focus on children's reactions. Eur Child Adolesc Psychiatry. https://doi.org/10.1007/s00787-021-01758-x

16. Golberstein E, Wen H, Miller BF (2020) Coronavirus disease 2019 (COVID-19) and mental health for children and adolescents. JAMA Pediatr 174:819. https://doi.org/10.1001/jamapediatrics. 2020.1456

17. Adduci A, Ferrari A, Grampa P, Giovanetti M, Massimino M (2021) How the COVID-19 pandemic has prevented children with cancer from pursuing their schooling in hospital or at home. Childs Nerv Syst 37:727-728. https://doi.org/10.1007/ s00381-020-05027-1

18. Ballestero MFM, Furlanetti L, de Oliveira RS (2020) Pediatric neurosurgery during the COVID-19 pandemic: update and recommendations from the Brazilian Society of Pediatric Neurosurgery. Neurosurg Focus 49(6):E2. https://doi.org/10.3171/2020.9. FOCUS20703

19. Khalafallah AM, Jimenez AE, Lee RP, Weingart JD, Theodore $\mathrm{N}$, Cohen AR et al (2020) Impact of COVID-19 on an academic neurosurgery department: the Johns Hopkins experience. World Neurosurg 139:e877-e884. https://doi.org/10.1016/j.wneu.2020. 05.167

20. Jean WC, Ironside NT, Sack KD, Felbaum DR, Syed HR (2020) The impact of COVID-19 on neurosurgeons and the strategy for triaging non-emergent operations: a global neurosurgery study. Acta Neurochir 162:1229-1240. https://doi.org/10.1007/ s00701-020-04342-5

21. Fraymovich S, Levine DA, Platt SL (2020) A blueprint for pediatric emergency resource reallocation during the COVID-19 pandemic: an NYC hospital experience. Pediatr Emer Care 36:452-454. https:// doi.org/10.1097/PEC.0000000000002203

22. Wellons JC, Grant G, Krieger MD, Ragheb J, Robinson S, Weprin B et al (2020) Editorial. Early lessons in the management of COVID-19 for the pediatric neurosurgical community from the leadership of the American Society of Pediatric Neurosurgeons. J Neurosurg Pediatr 26:1-2. https://doi.org/10.3171/ 2020.3.PEDS20215

23. D'Amico RS, Baum G, Serulle Y, Silva D, Smith ML, Wallack RA et al (2020) A roadmap to reopening a neurosurgical practice in the age of COVID-19. World Neurosurg 139:289-293. https:// doi.org/10.1016/j.wneu.2020.05.022

24. Molliqaj G, Schaller K (2020) How neurosurgeons are coping with COVID-19 and how it impacts our neurosurgical practice: report from Geneva University Medical Center. World Neurosurg 139:624-627. https://doi.org/10.1016/j.wneu.2020.04.149

25. Galarza M, Gazzeri R (2020) Letter: Collateral pandemic in face of the present COVID-19 pandemic: a neurosurgical perspective. Neurosurgery 87:E186-E188. https://doi.org/10.1093/neuros/ nyaa 155

26. Ahluwalia R, Rocque BG, Shannon CN, Blount JP (2020) The impact of imposed delay in elective pediatric neurosurgery: an informed hierarchy of need in the time of mass casualty crisis. Childs Nerv Syst 36:1347-1355. https://doi.org/10.1007/ s00381-020-04671-x

27. DeFazio JR, Kahan A, Fallon EM, Griggs C, Kabagambe S, Zitsman $\mathrm{J}$ et al (2020) Development of pediatric surgical decision-making guidelines for COVID-19 in a New York City children's hospital. J Pediatr Surg 55:1427-1430. https://doi.org/10.1016/j.jpedsurg.2020. 05.043
28. Aly A, Pettorini B (2021) COVID-19 lockdown presented a chance to evaluate emergency referrals to paediatric neurosurgical unit: a prospective cohort study. Childs Nerv Syst 37:729732. https://doi.org/10.1007/s00381-020-04985-w

29. Dyson EW, Craven CL, Tisdall MM, James GA (2020) The impact of social distancing on pediatric neurosurgical emergency referrals during the COVID-19 pandemic: a prospective observational cohort study. Childs Nerv Syst 36:1821-1823. https://doi.org/10. 1007/s00381-020-04783-4

30. Bram JT, Johnson MA, Magee LC, Mehta NN, Fazal FZ, Baldwin KD et al (2020) Where have all the fractures gone? The epidemiology of pediatric fractures during the COVID-19 pandemic. J Pediatr Orthop 40:373-379. https://doi.org/10.1097/ BPO.0000000000001600

31. Andalib A, Sanders MI, Sinha S (2021) Traumatic paediatric neurosurgical emergencies during the COVID-19 pandemic: experience in a single regional paediatric major trauma centre. Childs Nerv Syst 37:5-6. https://doi.org/10.1007/s00381-020-04902-1

32. Petrowski N, Cappa C, Pereira A, Mason H, Daban RA (2021) Violence against children during COVID-19: assessing and understanding change in use of helplines. Child Abuse Negl 116(Pt 2):104757. https://doi.org/10.1016/j.chiabu.2020.104757

33. Martinkevich P, Larsen LL, Græsholt-Knudsen T, Hesthaven G, Hellfritzsch MB, Petersen KK et al (2020) Physical child abuse demands increased awareness during health and socioeconomic crises like COVID-19: a review and education material. Acta Orthop 91:527-533. https://doi.org/10.1080/17453674.2020. 1782012

34. Meybodi KT, Habibi Z, Nejat F (2021) The effects of COVID-19 pandemic on pediatric neurosurgery practice and training in a developing country. Childs Nerv Syst 37:1313-1317. https://doi.org/10.1007/ s00381-020-04953-4

35. Ramakrishna R, Zadeh G, Sheehan JP, Aghi MK (2020) Inpatient and outpatient case prioritization for patients with neuro-oncologic disease amid the COVID-19 pandemic: general guidance for neuro-oncology practitioners from the AANS/CNS Tumor Section and Society for Neuro-Oncology. J Neurooncol 147:525-529. https://doi.org/10.1007/s11060-020-03488-7

36. Liu Q, Xu K, Wang X, Wang W (2020) From SARS to COVID19: what lessons have we learned? J Infect Public Health 13:16111618. https://doi.org/10.1016/j.jiph.2020.08.001

37. El-Ghandour NMF, Elsebaie EH, Salem AA, Alkhamees AF, Zaazoue MA, Fouda MA et al (2020) Letter: The impact of the coronavirus (COVID-19) pandemic on neurosurgeons worldwide. Neurosurgery 87:E250-E257. https://doi.org/10.1093/ neuros/nyaa212

38. Tomlinson SB, Hendricks BK, Cohen-Gadol A (2019) Immersive three-dimensional modeling and virtual reality for enhanced visualization of operative neurosurgical anatomy. World Neurosurg 131:313-320. https://doi.org/10.1016/j.wneu.2019.06.081

39. Ceraudo M, Balestrino A, Cama A, Macrina G, Piatelli G, Consales A (2021) Pediatric neurosurgery after the COVID-19 pandemic: management strategies from a single pediatric hospital in Italy. World Neurosurg 146:e1079-e1082. https://doi.org/10.1016/j.wneu.2020. 11.088

40. Audi A, AlIbrahim M, Kaddoura M, Hijazi G, Yassine HM, Zaraket H (2020) Seasonality of respiratory viral infections: will COVID-19 follow suit? Front Public Health 8:567184. https://doi. org/10.3389/fpubh.2020.567184

41. Jones KE, Patel NG, Levy MA, Storeygard A, Balk D, Gittleman JL et al (2008) Global trends in emerging infectious diseases. Nature 451(7181):990-993. https://doi.org/10.1038/nature06536

42. FAO - News Article (2021) Surge in disese of animal origin necessitates new approach to health - report. Accessed 03/07/21 avaliable at http://www.fao.org/news/story/en/item/210621/icode/ 
43. Zinstag J, Schelling E, Waltners-Toews D, Tanner M (2011) From "one medicine" to "one health" and systemic approaches to health and well-being. Prev Vet Med 101:148-156. https://doi.org/10. 1016/j.prevetmed.2010.07.003

Publisher's Note Springer Nature remains neutral with regard to jurisdictional claims in published maps and institutional affiliations.
In memoriam of: James T. Goodrich, Karl Kothbauer, Robin P. Humphreys, and William Harkness, whose examples and leadership strongly contibuted to shape ISPN over years. All HCP, the real heroes of this war who gave up their security and sacrificed their lives during the pandemic. 